Juliano de Araújo

CASSIANO $^{1}$

Ricardo Henri Rodrigues

DESTÉFANO ${ }^{2}$

Marta dos Santos

BARACHO $^{1}$

Irenilza de Alencar $\mathrm{NÄ} \ddot{A} S^{1}$

Douglas D'Alessandro

SALGADO $^{1}$

Correspondência para:

Marta dos Santos Baracho, Faculdade de Engenharia Agrícola/UNICAMP, Caixa Postal: 6011; 13083-970, Campinas-SP martbaracho@yahoo.com.br

Recebido para publicação: 27/08/2005 Aprovado para publicação: 07/03/2008

\title{
Análise de adesão do fungo entomopatogênico Metarhizium anisopliae para o controle de Alphitobius diaperinus (cascudinho) em instalações avícolas
}

\author{
1 - Departamento de Construções Rurais e Ambiência da Faculdade de \\ Engenharia Agrícola da Universidade Estadual de Campinas, Campinas - SP \\ 2 - Departamento de Genética e Evolução do Instituto de Biologia da \\ Universidade Estadual de Campinas, Campinas - SP
}

\begin{abstract}
Resumo
Este trabalho permitiu a construção de um modelo estatístico para a adesão de conídios do fungo Metarbizium anisopliae diante de diferentes níveis de concentração e tempo, além de avaliar seu potencial para o controle do cascudinho (Alphitobius diaperinus), importante praga da avicultura, causadora de danos às aves pelos ferimentos no trato digestivo e pela transmissão de várias doenças. $\mathrm{O}$ estudo da adesão sobre o tegumento é de grande importância, pois a adesão representa um evento complexo, sendo o primeiro do ciclo das relações patógeno-hospedeiro que ocorre após a deposição do fungo sobre o inseto e visa a preparação do local para a fase de penetração. Insetos adultos do cascudinho foram expostos a três concentrações do fungo: $1 \times 10^{3}, 1 \times 10^{6}$ e $1 \times 10^{9}$ conídios/mL, sendo 5,10 e 15 minutos de exposição em cada concentração. Para verificar o potencial de controle de $M$. anisopliae, os insetos foram colocados para caminhar sobre uma massa de conídios crescida em meio BDA por 10 minutos, resultando num potencial de inóculo de $8,1 \times 10^{8}$ conídios $/ \mathrm{mL}$, a mortalidade foi avaliada durante 21 dias consecutivos, onde se verificou uma mortalidade de $74 \%$ em larvas após $48 \mathrm{~h}$, e $50 \%$ de mortalidade em adultos após 15 dias de exposição ao fungo. A análise de variância (ANOVA) mostrou que existe influência e interação de ambos os efeitos: concentração e tempo.
\end{abstract}

\section{Introdução}

A avicultura comercial brasileira representa um importante setor na economia nacional, sendo formada pelos setores de aves de reprodução, de produção de ovos de mesa e de produção de carne. Além do suprimento de alimentos de qualidade à população brasileira, ela desempenha um papel internacional significativo: sendo o terceiro produtor mundial e o segundo maior exportador. No Brasil a avicultura tem gerado elevada participação no PIB brasileiro respondendo por $1,2 \%$ do que é produzido no país.

Segundo De Las Casas et al. ${ }^{1}$, o cascudinho, Alphitobius diaperinus, representa grandes prejuízos à avicultura causando danos às aves e resultando em perdas de produção. Esta espécie se origina em regiões tropicais e infesta os galpões de aves domésticas, reduzindo a conversão alimentar das aves jovens por provocar ferimentos no sistema digestório, uma vez que é ingerido em grande quantidade juntamente com a ração balanceada. Além disso, os besouros foram considerados capazes de reservarem diversos agentes infecciosos como Salmonella, Aspergilus spp., Streptococcus spp., etc e transmitirem doenças como Newcastle, Influenza Aviária, Doença Bursal Infecciosa, Doença de Marek. 2,3,4 
Em países de clima temperado o Alphitobius diaperinus é considerado uma praga estrutural devido aos danos causados por seu hábito de antes da pupação perfurar as placas do poliuretano e do poliestireno, materiais utilizados nas paredes das vertentes para a isolação térmica. ${ }^{5,6}$

O controle deste inseto é uma necessidade, pois propiciaria a diminuição de custos e aumentaria a produção e a qualidade do produto final oferecido ao consumidor. Estes aspectos reforçam a necessidade do seu controle, que não é fácil, por tratar de uma espécie dispersora capaz de adaptar sua fisiologia e seus hábitos às condições existentes nos galpões de frango, os quais constituem uma extensão do seu habitat natural. O sistema intensivo de produção avícola oferece condições favoráveis para seu desenvolvimento, visto que o inseto encontra no interior do aviário, abundância de alimento, umidade e temperatura elevada e locais para se abrigar e reproduzir. ${ }^{7,8}$

O uso de produtos químicos, embora eficiente, pode causar problemas de intoxicação às aves, produtor e ao consumidor final na forma de resíduos tóxicos, além de oferecer riscos ao ecossistema local. Sendo assim, o Manejo Integrado de Pragas (MIT) vem encorajando a diminuição desses produtos e fornecendo opções de controle harmonioso insetospraga, estabelecendo baixos níveis populacionais de maneira que não causem danos econômicos. ${ }^{9}$

O grande desafio desse novo milênio é buscar a evolução, gerando tecnologias que contribuam para o aumento da produtividade e da competitividade do produtor, sem causar danos ao ambiente e comprometer os recursos naturais. Não obstante, o controle microbiológico com fungos entomopatôgenicos mostra-se uma alternativa segura de redução populacional desta praga, pois segundo Crawford, Brooks e Arends ${ }^{10}$ os entomopatôgenos são inócuos aos animais homeotérmicos.

Sengundo Burgues ${ }^{11}$, o M. anisopliae está sendo estudado e desenvolvido como pesticida microbiano. O desenvolvimento de agentes para biocontrole requer $\mathrm{O}$ conhecimento das etapas envolvidas no processo de infecção fungo-hospedeiro.

St. Leger et al. ${ }^{12}$ estudaram o processo de adesão conidial e formação de apressórios de Metarbižium anisopliae que é de fundamental importância, uma vez que representa o primeiro evento da relação fungo-hospedeiro e visa à penetração no inseto. A interação conídio-cutícula envolve um complexo específico através da ação de glicoproteínas, enzimas extracelulares e da ação de forças eletrostáticas e hidrofóbicas. ${ }^{13,14}$

Esse trabalho teve como objetivo verificar a patogenicidade da linhagem $\mathrm{E}_{\mathrm{g}}$ de Metarbizium anisopliae e a influência de diferentes níveis de concentração e tempo de exposição ao patógeno no processo de adesão conidial.

\section{Material e Método}

Foram realizados experimentos em laboratório utilizando-se insetos provenientes da Granja Cláudia, localizada no município de Louveira - Estado de São Paulo. Foram coletados insetos adultos e larvas os quais foram mantidos em laboratório.

Utilizou-se a linhagem $\mathrm{E}_{0}$ do fungo Metarhizium anisopliae, isolada pelo pesquisador Aires Ventura na década de 70 de Deois flavopicta. Inicialmente foram produzidos conídios em meio $\mathrm{BDA}^{15} \mathrm{e}$ incubados em estufa à $28^{\circ} \mathrm{C}$ por 10 dias.

Foram utilizados 50 insetos adultos e 50 larvas, os quais foram colocados por 10 minutos em placa de Petri contendo a linhagem $\mathrm{E}_{9}$ do fungo $M$ anisopliae a uma concentração de $8,1 \times 10^{8}$ conídios, sendo em seguida individualizados em frascos limpos e secos contendo um pouco de alimento (farelo de trigo).

Um grupo de insetos testemunha que recebeu o mesmo tratamento, exceto o patógeno, foi mantido nas mesmas condições servindo como controle.

Insetos tratados e não tratados foram mantidos em estufa à $28^{\circ} \mathrm{C}$ e com umidade relativa acima de $80 \%$, controlados durante 
21 dias, sendo feita a contagem diária dos mortos.

Foram coletados insetos tratados com o fungo para a avaliação da dose efetiva (potencial de inóculo) a que foram expostos. Destes insetos 12 foram submetidos à lavagem intensa com espalhante adesivo, solução de Tweenâ 80 a 0,01\% (v/v), em vortex por 5 minutos e dessa solução aliquotou-se $1 \mathrm{~mL}$ e fez-se diluições seriadas. Da maior diluição fez-se a contagem em hematímetro (câmara Neubauer), obtendose assim o número de conídios que efetivamente aderiram aos insetos.

Os insetos mortos foram congelados a $-20^{\circ} \mathrm{C}$. Para confirmação da causa da mortalidade eles foram lavados durante 20 minutos em solução de $\mathrm{NaHClO}$ a $2,5 \%$ $(\mathrm{v} / \mathrm{v})$, depois lavados duas vezes por 15 minutos em solução de Tweenâ 80 a $0,01 \%$ (v/v) e em seguida lavados por três vezes em água destilada esterilizada, sendo colocados em papel filtro previamente esterilizado para secarem. Estes procedimentos contribuíram para remover possíveis agentes patológicos que poderiam estar aderidos ao tegumento externo dos insetos e larvas. Os insetos foram então colocados em placas de Petri contendo meio $\mathrm{BDA}^{15}$, as quais foram levadas para a estufa a uma temperatura de $28^{\circ} \mathrm{C}$, onde se analisou após 48 a 72 horas se houve crescimento do fungo.

Para a análise da adesão dos conídios sobre o cascudinho o experimento foi delineado como um fatorial $3 \times 3$, onde os insetos foram expostos a três níveis de concentrações do fungo sendo $C_{1}=1 \times 10^{3}$, $\mathrm{C}_{2}=1 \times 10^{6}$ e $\mathrm{C}_{3=} 1 \times 10^{9}$ conídios $/ \mathrm{mL}$ em placa de Petri contendo papel de filtro por onde caminharam por $\mathrm{T}_{1}=5 \mathrm{~min}, \mathrm{~T}_{2}=10$ min e $T_{3}=15$ min em cada concentração. Foram realizadas três repetições aleatórias com sete insetos em cada concentração e tempo.

Os insetos foram acondicionados em tubos de ensaio e congelados a $-20^{\circ} \mathrm{C}$. Em seguida foram lavados em solução de Tweenâ 80 a $0,01 \%(\mathrm{v} / \mathrm{v})$ em vortex por 5 minutos sendo feita a contagem dos conídios em hematímetro (câmara Neubauer). Os dados obtidos foram analisados através da regressão com variável Dummy ${ }^{16} \mathrm{e}$ ANOVA deste modelo. A modelagem foi realizada através do software Minitab $15^{\circledR}$.

\section{Resultados e Discussão}

Os resultados obtidos nos testes de patogenicidade da linhagem $\mathrm{E}_{9}$ de $M$. anisopliae mostraram o potencial entomopatogênico deste fungo sobre o cascudinho, resultando numa mortalidade de $98 \%$ em larvas e $62 \%$ em insetos adultos, o que evidencia a potencialidade deste deuteromiceto para ser testado em programas de controle microbiano, pois já é de amplo conhecimento seu largo espectro de ação sobre muitos insetos pragas. ${ }^{17}$

Dos insetos coletados para cálculo do potencial de inóculo obteve-se 9,1 x $10^{6}$ conídios/mL para as larvas e 2,2 x $10^{6}$ conídios/mL para os insetos adultos.

Para o teste de adesão, a análise de Variância mostrou que houve efeito significativo da interação tempo $\mathrm{X}$ concentração. Influência da concentração e do tempo $(p=0,000$, significativo $a=5 \%)$, porém com o teste de interação mostrando significância só se pode avaliar a adesão frente à combinação dos níveis de concentração e tempo.

Durante a análise de resíduos desse modelo foi verificado a necessidade de transformação $\mathbf{L n}$ (logaritmo neperiano) na variável do " $\mathrm{N}^{\circ}$ de conídios", atendendo assim a pressuposição de homocedasticidade da variância do modelo, bem com as outras pressuposições: normalidade e independência. ${ }^{16}$

Aos dados transformados aplicou-se uma análise de variância para o modelo de regressão. O resultado desta análise é apresentado na tabela 1 , onde se constata: o valor de F para Concentração foi de 6947,54*, significativo. Constata-se também que houve efeito de tempo, $\mathrm{F}=327,45^{*}$, e de interação de concentração e tempo, $\mathrm{F}=$ *7,65. A análise mostra que o número de conídios variou significativamente nas concentrações em estudo, e que as condições 
de tempo de exposição utilizado neste trabalho apresentaram diferenças estaticamente com relação ao número de conídios aderidos.

A análise de regressão apresentada na tabela 1 mostra que o modelo com a transformação logaritma, além de atender todas as pressuposições exigidas para a validação, foi altamente significativo $(\mathrm{P}<0,0001)$ e obtendo ainda um elevado coeficiente de determinação $\left(\mathrm{R}^{2}=99,98 \%\right)$, demonstrando um excelente ajuste das variáveis.

A tabela 1 denota que os níveis das diferentes de concentrações provocam efeitos significativos no $\operatorname{Ln}\left(\mathrm{N}^{\circ}\right.$ conídios aderidos). O tempo, que é uma variável regressora, também exerceu influência significativa sobre a variável resposta. E a interação significativa entre os níveis de concentração e o tempo de exposição denota que a influência do tempo é alterada dependendo do nível de concentração.

A equação do modelo encontrado pode ser escrita da seguinte forma: Ln $\left(\mathrm{N}^{\circ}\right.$ conídios $)=$

$$
\begin{aligned}
& 8,326-6,049_{\left(\mathrm{C} 1=10^{3}\right)}+2,562_{\left(\mathrm{C} 2=10^{6}\right)}+ \\
& 0,061 \cdot \text { Tempo }+0,018 \cdot \text { Tempo }_{\left(\mathrm{C} 2=10^{6}\right)} \\
& \text { Interpretação: }
\end{aligned}
$$

- o primeiro parâmetro estimado $(8,326)$ refere-se a média geral do $\operatorname{Ln}\left(\mathrm{N}^{\circ}\right.$ Conídios);

- o segundo refere-se a variável Dummy, sendo o efeito diferencial devido à Concentração C1;

- o terceiro refere-se também a variável Dummy, sendo o efeito diferencial devido à Concentração C2;

- o quarto é o coeficiente angular geral para o Tempo de exposição (independente da concentração);

- o quinto é o efeito de interação (Concentração e Tempo de exposição), isto é, o incremento do coeficiente angular para o Tempo devido à Concentração C2.

Em outras palavras, utilizando um único modelo com variável Dummy, foram extraídos os modelos de regressão para os três níveis de concentração, apresentados na figura 1:

- Modelo para C1: 2,277 + 0,061·Tempo;

- Modelo para C2: 10,888 + 0,079 -Tempo;

- Modelo para C3: 11,813 + 0,061·Tempo.

Assim constatou-se que o efeito de concentração é significativo devido aos diferentes interceptos e que a variável tempo tem influência sobre o $\mathrm{Ln}\left(\mathrm{N}^{\circ}\right.$ conídios aderidos) devido à significância dos coeficientes angulares. E ainda, a interação significativa entre concentração e tempo resultou num incremento do coeficiente angular do modelo da concentração $\mathrm{C} 2$, ou seja esta reta ajustada não é paralela às demais. Isto é, o efeito do tempo sobre o Ln ( ${ }^{\circ}$ conídios aderidos) é maior ainda na concentração $\mathrm{C} 2$, quando comparada às demais concentrações como se pode constatar na figura 1. A ilustração gráfica desse modelo é análoga ao gráfico da figura 1.

\section{Conclusões}

A linhagem $\mathrm{E}_{0}$ do fungo entomopatogênico Metarbiżium anisopliae mostrou-se altamente patogênica ao cascudinho (Alphitobius diaperinus).

Para a adesão foi mostrada a influência significativa da concentração e tempo de exposição ao patógeno. Para as

Tabela 1 - Análise de variância para o modelo de Regressão com variável Dummy

\begin{tabular}{cccccc}
\hline $\begin{array}{c}\text { Causa da } \\
\text { variação }\end{array}$ & GL & SQ & SQ-ajuste & QM-ajuste & F \\
\hline Concentração & 2 & 508,01 & 71,14 & 35,57 & $6947,54^{*}$ \\
Tempo & 1 & 1,68 & 1,68 & 1,68 & $327,45^{*}$ \\
Concentração & 2 & 0,08 & 0,08 & 0,04 & $7,65^{*}$ \\
x Tempo & 21 & 0,11 & 0,11 & 0,01 & \\
Resíduo & 26 & 509,87 & & & \\
\hline Total & 26 & & \\
\hline
\end{tabular}




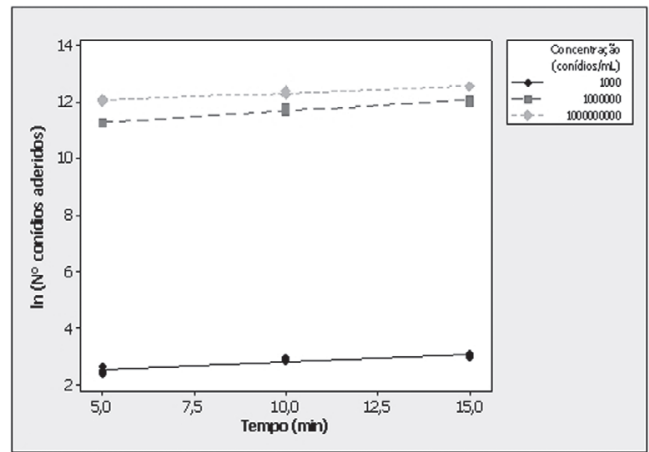

Figura 1 - Representação gráfica de dispersão do Ln $\left(\mathrm{N}^{\circ}\right.$ conídios) em função do Tempo e da Concentração

concentrações menores $\left(1 \times 10^{3}\right)$ observouse a não influência do tempo de exposição sobre a adesão e para as maiores houve grande influência, mostrando ainda, que a melhor combinação de concentração e tempo de exposição que fornece maior eficácia com relação a capacidade de aderência é a de maior concentração e tempo.

Esses resultados indicam a possibilidade da implementação de novas tecnologias de controle desta praga, objetivando um menor custo financeiro e impacto ambiental, além de agregação de valor à produção avícola.

\section{Agradecimentos}

Ao SAE/UNICAMP pela bolsa trabalho, e a Profa. Dra. Vera N. Solferini (LDG/DGE/IB/ UNICAMP), pela utilização de seu laboratório LDG.

\section{Analysis of entomogenous fungus Metarhizium anisopliae to control Alphitobius diaperinus in poultry buildings.}

\section{Abstract}

This present research work has allowed a statistical modeling for conidial adhesion and the potential fungus Metarbizium anisopliae ability to lesser the mealworm Alphitobius diaperinus control, that is an important pest of poultry production, which causes damage to the birds by the development of injuries in the digestion tract, and yet it serves as vector of many avian pathogens. The study of the host cuticle adhesion is very important, whereas the adhesion process represents a complex event, as it is the first occurrence in the pathogenhost cycle, taking place after fungus deposition on the insect, aiming the penetration phase. Adult insects of $A$. diaperinus were exposed to three concentrations of the fungus: $1 \times 10^{3}, 1 \times 10^{6}$ e $1 \times 10^{9}$ conidia $/ \mathrm{mL}$, for 5, 10 and 15 minutes of exposition to each conidial concentration. In order to verify the ability control of $M$. anisopliae, the insects were forced to the displacement on the conidial mass growth onto PDA medium for 10 minutes, resulting in a $8,1 \times 10^{8}$ conidia $/ \mathrm{mL}$ inocullum potential, and the mortality was monitored during 21 days, obtaining $74 \%$ of mortality in larvae after $48 \mathrm{~h}$ and $50 \%$ of mortality in adults after 15 days, under fungus exposition. ANOVA has showed that there is influence and interaction between both effects: concentration and time.

\section{Referências}

1 DE LAS CASAS, E.; HAREIN, P. K.; DESHMUCK, D. R.; POMEROY, B. S. Relationship between the lesser mealworm, foul pox, and Newcastle disease virus in poultry. Journal of Economic Entomology, v. 69, p. 775-779, 1976.
Key words:

Poultry.

Microbiological control. Sanity.
2 DESPINS, J. L.; AXTELL, R. C. Feeding behavior and growth of broiler chicks fed larvae of the darkling beetle, Alphitobius diaperinus. Poultry Science, v. 74, p. 331336, 1995.

3 DESPINS, J. L.; AXTELL, R. C.; RIVES, D. V.; GUY, J. S.; FICKEN, M. D. Transmission of enteric pathogens of turkeys by darkling beetle larva (Alphitobius diaperinus). 
Journal of Applied Poultry Research, v. 3, p. 61-65, 1994.

4 McALLISTER, J. C.; STEELMAN, C. D.; NEWBERRY, L. A.; SKEELES, J. K. Isolation of infectious bursal disease virus from the lesser mealworm, Alphitobius diaperinus (Panzer). Poultry Science, v. 74, p. 45-49, 1995.

5 MILLER, J. P. That crunchy stuff in you cereal bowl may not be granola. Beetles invade an Ohio town when chicken farms plan for fly control goes awry. Wall Street Journal, p. A.1, nov. 3, 1997.

6 VAUGHAN, J. A.; TURNER, E. C.; RUSZLER, P. L. Infestation and damage of poultry houses insulation by the lesser mealworm. Alphitobius diaperinus (Panzer). Poultry Science, v. 63, p. 1094-1100, 1984.

7 CHERNAKI, A. M.; ALMEIDA, L. M. Morfologia dos estágios imaturos e do adulto de Alphitobius diaperinus (Coleóptera: Tenebrionidae). Revista Brasileira de Zoologia, v. 18, p. 351-363, 2001.

8 SALIN, C.; RENAULT, D.; VANNIEN, G.; VERNON, P. A sexually dimorphic response in supercooling temperature, enhanced by starvation, in the lesser mealworm Alphitobius diaperinus (Coleoptera: Tenebrionidae). Journal of Thermal Biology, v. 25, p. 411-418, 2000

9 PAPACEK, D.; SMITH, D. Manejo integrado de pragas nos citros: linhas gerais de um programa de MIP em Queensland, Austrália. In: SEMINÁRIO INTERNACIONAL DE CITROS-MIP, 3., 1994. Bebedouro. Anais... Bebedouro: FUNEP, 1994. p. 153175.

10 CRAWFORD, P. J.; BROOKS, W. M.; ARENDS, J. J. Efficacy of field-isolated strains of Beauveria bassiana
(Moniliales: Moniliacea) as microbial control agents of the lesser mealworm (Coleoptera: Tenebrionidae). Journal of Economic Entomology, v. 91, p. 1295-1301, 1998.

11 BURGESS, H. D. Microbial control of pests and plant diseases 1970-1980. New York: Academic Press, 1981. p. 441-572.

12 ST. LEGER, R. J.; GOETTEL, M.; ROBERTS, D. W.; STAPLES R. C. Prepenetration events during infection of host cuticle by Metarhizium anisopliae. Journal Invertebrate Pathology, v. 58, p. 168-179, 1991.

13 FARGUES, J. Adhesion of the fungal spore to the insect cuticle in relation to pathogenicity. In: AIST, J. R.; ROBERTS, D. W. (Ed.). Infection processes of fungi. Belaggio, Italy: Rockefeller Foundation Study Center, 1984. p. 90-110.

14 TERHUNE, B. T.; HOCH, H. C. Substrate hydrophobicity and adherence of Uromyces uredospores and germlings. Experimental Mycology, v. 17 , p. $241-252,1993$.

15 INSTITUTE OF SEED TESTING ASSOCIATION. Rules for seed testing. Proceedings of the International Seed Testing Association, v. 31, p. 1-152, 1966.

16 SALGADO, D. D. Modelo estatístico para predição de bem-estar de reprodutoras de frango de corte baseado em dados de ambiente e análise do comportamento. 2006. 113 f. Dissertação (Mestrado em Construções Rurais e Ambiência) - Faculdade de Engenharia Agrícola, Universidade Estadual de Campinas, 2006.

17 ALVES, S. B. Controle microbiano de insetos. 2. ed. Piracicaba: FEALQ/USP, 1998. 1163 p. 